\title{
La longitud del cuello uterino a mitad de la gestación se asocia al riesgo de cesárea
}

\author{
Cervical Length at Mid-Pregnancy and the Risk of Primary Cesarean Delivery
}

\section{Objetivo}

Evaluar en primíparas si la longitud cervical (LC) a la mitad del embarazo se asocia a un mayor riesgo de cesárea intraparto (no programada) al término.

\section{Diseño, lugar y pacientes}

Cohorte retrospectiva sobre un análisis secundario de datos obtenidos de estudios multicéntricos sobre rastreo e intervenciones durante el embarazo conducidos entre 1998 y 2006 en ocho hospitales de Londres y sus alrededores, Gran Bretaña. Ingresaron 27.472 primíparas cuyos embarazos finalizaron de término con un recién nacido vivo que habían sido evaludas con ecografía transvaginal a una media de 23 semanas de edad gestacional (rango intercuartilo 22,5 a 23,2 ) y habían presentado una LC mayor a $15 \mathrm{~mm}$. Fueron excluidas las pacientes con cesáreas programadas.

\section{Medición de resultados principales}

Tasa de cesáreas intraparto en embarazos de término estratificada en cuatro subgrupos según la LC a la mitad del embarazo. Se hizo un análisis multivariable ${ }^{\star}$ ajustando por la edad materna, el índice de masa corporal, la condición de fumadora, la raza, la edad gestacional al parto, la forma de inicio del trabajo de parto, el percentilo del peso del recién nacido (según tablas para edad gestacional y sexo) y el hospital.
Smith G y col. N Engl J Med. 2008 Mar 27;358(13):1346-53.

\section{Resultados}

Comparadas con las mujeres cuya LC fue de 16 a 30mm, quienes tuvieron una LC mayor a $40 \mathrm{~mm}$ tuvieron una mayor chance $(68 \%)$ de ser sometidas a cesárea, sin asociaciones significativas en los cuartilos intermedios de LC. Los resultados principales se resumen en la tabla 1.

Tabla 1: asociación entre la longitud cervical a las 23 semanas de edad gestacional y la tasa de cesárea intraparto (no programada).

\begin{tabular}{c|c|c}
\hline $\begin{array}{c}\text { Longitud cervical a la } \\
\text { mitad del embarazo }\end{array}$ & $\begin{array}{c}\text { Tasa de cesárea } \\
\text { intraparto }\end{array}$ & OR (IC95\%) \\
\hline 16 a $30 \mathrm{~mm}$ & $16,0 \%$ & Referencia \\
\hline 31 a $35 \mathrm{~mm}$ & $18,4 \%$ & NS \\
\hline 36 a $39 \mathrm{~mm}$ & $21,7 \%$ & \\
\hline Más de $40 \mathrm{~mm}$ & $25,7 \%$ & $1,68(1,53$ a 1,84$)$ \\
\hline
\end{tabular}

NS: no significativo.

\section{Conclusiones}

Las pacientes con LC mayor a $40 \mathrm{~mm}$ a las 23 semanas de gestación tendrían algo menos del doble de probabilidad de ser sometidas a cesárea no programada que las pacientes con LC entre 16 y $30 \mathrm{~mm}$.

Palabras claves: cesárea, riesgo, longitud cervical, estudio de cohorte. Key words: cesarea, risk, cervical lenght, cohort study.

Fuentes de financiamiento: Fetal Medicine Foundation. No reportan conflictos de interés.

\section{Comentario}

Debido a que la tasa de cesáreas en primíparas es un condicionante importante de la tasa de cesáreas global; y considerando que el parto prolongado es la principal causa de cesárea intraparto, este grupo de investigadores intentó evaluar si la LC es un factor pronóstico para el riesgo de cesárea intraparto al término, en mujeres primíparas.

Según los autores, el riesgo de necesitar una cesárea intraparto empieza a crecer cuando la longitud del cuello a las 23 semanas de gestación es mayor a $25 \mathrm{~mm}$ y sigue aumentando hasta casi duplicarse para los cuellos de $50 \mathrm{~mm}$ o más -nótese que para este comentario no utilizan los mismos puntos de corte que para elaborar las cuatro categorías.

Si bien los resultados mostrados son estadísticamente significativos, los autores no refieren si quienes atendieron los nacimientos conocían la medición del cuello de esa mujer, no aclarando tampoco si dicha medición fue realizada por dos observadores independientes y si fue evaluada la variación interobservador -como es habitual en los estudios que involucran medición con ultrasonido.

Además de las limitaciones inherentes a los estudios de análi- sis secundario; ellos mismos comentan que es posible que la asociación encontrada refleje, un confundidor residual debido a un fracaso al medir variables maternas importantes, o algún confundidor no medido. Hubiera sido interesante conocer la LC de esas pacientes en una fecha más cercana al parto', para evaluar cómo correlacionan ambas mediciones en la misma paciente en diferentes momentos del embarazo. Por estas razones nuevas investigaciones serán necesarias para confirmar la hipótesis.

\section{Conclusiones de la comentadora}

Si bien este estudio es interesante, hoy no tiene repercusión en la práctica clínica. Sin embargo, seguramente abrirá puertas para futuras investigaciones, a fin de confirmar si esta asociación realmente existe; y en caso afirmativo determinar la causa -los autores proponen un desarrollo disfuncional del útero en etapas tempranas del embarazo-, y si así fuera, buscar alguna terapéutica.

Lic. Ana Mara Bonotti [ Instituto de Efectividad Clínica y Sanitaria (Grupo Madre y Niño) ambonotti@gmail.com ]

Recibido el 02/06/08 y aceptado el 28/07/08.

Bonotti A. a longitud del cuello uterino a mitad de la gestación se asocia al riesgo de cesárea.Romano M. La terapia ocupacional mejora las actividades personales de la vida diaria de quienes sufrieron un accidente cerebro-vascular. Evid. actual. práct. ambul; $11(4): 111$, Jul-Ago.2008. Comentado de: Smith G y col. Cervical length at mid-pregnancy and the risk of primary cesarean delivery $\mathrm{N}$ Engl $\mathrm{J}$ Med. $2008 \mathrm{Mar}$ 27;358(13):1346-53.PMID: 18367737. Disponible en URL: http://content.nejm.org/cgi/reprint/358/13/1346.pdf (último acceso 28/0//08).

\section{Referencias}

1. Ramanathan G, y col. Ultrasound examination at 37 weeks' gestation in the prediction of pregnancy outcome: the value of cervical assessment. Ultrasound Obstet Gynecol 2003;22:598-60. 